\title{
Letter: High-level of Heteroplasmy in the Mitochondrial Cox1- Minichromosome of the Human Body Louse, Pediculus humanus, and the Human Head Louse, Pediculus capitis
}

\author{
Kate Herd ${ }^{1, *}$, Stephen C. Barker ${ }^{1}$ and Renfu Shao ${ }^{1,2}$ \\ ${ }^{I}$ The University of Queensland, School of Chemistry and Molecular Biosciences, Queensland 4072, Australia \\ ${ }^{2}$ School of Science, Education and Engineering, University of the Sunshine Coast, Maroochydore, Queensland, \\ Australia
}

\begin{abstract}
The mitochondrial (mt) genome of bilateral animals typically consists of a single chromosome, $\sim 16 \mathrm{~kb}$ long, and contains 37 genes. Variation in $\mathrm{mt}$ gene sequence within an individual, i.e. heteroplasmy, is common in bilateral animals but usually occurs at very low levels. In the lineage that led to the human body louse, the typical $\mathrm{mt}$ chromosome has fragmented into 18 minichromosomes: each minichromosome is 3 to $4 \mathrm{~kb}$ long and contains 1 to 3 genes and a noncoding region. To understand the presence and the level of heteroplasmy in fragmented mt genomes, we cloned and sequenced seven copies of full-length coxl-minichromosome of a human body louse and a human head louse. We found 17 heteroplasmic sites in the coding region and 118 heteroplasmic sites in the non-coding region of the coxlminichromosome. The level of heteroplasmy in the human lice appears to be much higher than that in other animals that have the typical $\mathrm{mt}$ genome. We propose that recombination between different minichromosomes of the fragmented $\mathrm{mt}$ genome may contribute to the high-level of heteroplasmy in the human lice.
\end{abstract}

Keywords: Coxl, genome, heteroplasmy, mitochondrial minichromosome, Pediculus capitis, Pediculus humanus.

\section{INTRODUCTION}

Mitochondrial (mt) genomes of bilateral animals usually consist of a single circular chromosome, which is $\sim 16 \mathrm{~kb}$ in size and contains 37 genes [1]. In the lineage that led to the human body louse, Pediculus humanus, however, the single $\mathrm{mt}$ chromosome typical of animals has fragmented into 18 minichromosomes [2]. Each minichromosome is 3 to $4 \mathrm{~kb}$ long and has 1 to 3 genes and a non-coding region (NCR). Analyses of the sequence-reads generated by the Human Body Louse Genome Project revealed substantial sequence variation in the NCRs and numerous polymorphic sites in the coding regions of mt minichromosomes [2]. It is not known, however, whether the observed sequence variation and the polymorphic sites are between different individuals or within an individual, i.e. heteroplasmy, because the Human Body Louse Genome Project used the DNA extracted from $\sim 100$ nymphs [3]. In the present study, we sequenced entirely seven copies of the coxl-minichromosome from an individual human body louse and an individual human head louse. We report here the remarkable level of heteroplasmy in the coxl-minichromosome of these lice.

\section{MATERIALS AND METHODS}

Total DNA was extracted from an adult human body louse of the Orlando strain and an adult human head louse

*Address correspondence to this author at the The University of Queensland, School of Chemistry and Molecular Biosciences, Queensland 4072, Australia; Tel: 008184 9362112-5256; Fax: 008184 9362024;

E-mail: kate.herd@uqconnect.edu.au from Brisbane with DNeasy Tissue kit (QIAGEN). Total DNA and TaKaRa LA Taq enzyme were used in PCR amplification. A forward primer, $\mathrm{PHC} 1 \mathrm{~F}(\mathrm{KH})\left(5^{\prime}\right.$-CAGCCTTTTTATTATTACTGTCACTTCCAG-3'), and a reverse primer, LC1RA (5'-GACTGCCTTTATTTTGCTGGAGAGTGTTGG-3'), were used in PCRs to amplify the entire coxl-minichromosome except a 3-bp gap between the two primers (Fig. 1A). The PCR conditions were: $1 \mathrm{~min}$ at $96^{\circ} \mathrm{C}$, then 35 cycles of $30 \mathrm{sec}$ at $96^{\circ} \mathrm{C}, 30 \mathrm{sec}$ at $58^{\circ} \mathrm{C}$ and $4 \mathrm{~min}$ at $68^{\circ} \mathrm{C}$, followed by $8 \mathrm{~min}$ at $72^{\circ} \mathrm{C}$. Negative controls were always included to ensure no amplicons were contaminated. PCR products were purified with S.N.A.P. ${ }^{\mathrm{TM}}$ UV-Free Gel Purification Kit (Invitrogen). Purified PCR products were cloned with a pGEM-T Easy Vector System and Escherichia coli JM109 Competent Cells (Promega). E. coli colonies were screened by PCR with M13F and M13R primers for DNA inserts of expected size (3-4 kb). We selected at random seven $E$. coli colonies that contained DNA inserts of expected size and sequenced these inserts entirely by primer walking. Five of these inserts were from the coxlminichromosome of the human body louse and two inserts were from the coxl-minichromosome of the human head louse. The sequences of these seven inserts were deposited in GenBank under accession numbers HM357241 to HM357247. A direct comparison of the heteroplasmy between Pediculus humanus and Pediculus capitis was not conducted, due to the differing number of clones, however, Graphpad software (Graphpad software Inc.) was used to conduct a pairwise $\mathrm{T}$ test analysis of the quantity of heteroplasmic sites detected in lice compared to other insects. 


\section{RESULTS}

The five copies of coxl-minichromosome we sequenced from the human body louse are 3554, 3557, 3558, 3559 and 3560 bp long, respectively. Each copy of the coxlminichromosome has a coding region, which contains only coxl gene, and a non-coding region (Fig. 1A). The coding regions of the five copies of coxl-minichromosome have the same length, $1572 \mathrm{bp}$; the non-coding regions, however, vary

B

\begin{tabular}{|c|c|}
\hline & 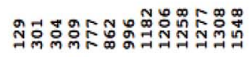 \\
\hline Clone 1 & GGCCCATTATTTT \\
\hline & AGTTTTTTATTAT \\
\hline Clon & AАTTTATCATTAT \\
\hline & AGTTTATTAT \\
\hline Clone 5 & АGTTTACTGC \\
\hline & 3113313 \\
\hline
\end{tabular}

C slightly in length from $1982 \mathrm{bp}$ to $1988 \mathrm{bp}$. Among the five copies of coxl-minichromosomes, there are 13 heteroplasmic sites in the coding region (Fig. 1B), i.e. in the coxl gene, and 73 heteroplasmic sites in the non-coding region (Fig. 1C). Four of the 13 heteroplasmic sites in the coxl gene are at the first codon position, one heteroplasmic site is at the second codon position, and eight heteroplasmic sites are at the third codon position (Fig. 1B).

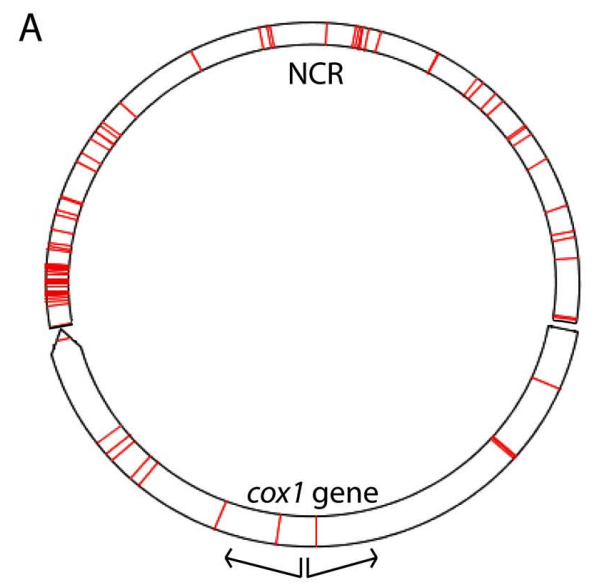

Clone 1

Clone 2

Clone 3

Clone 4

Clone 5

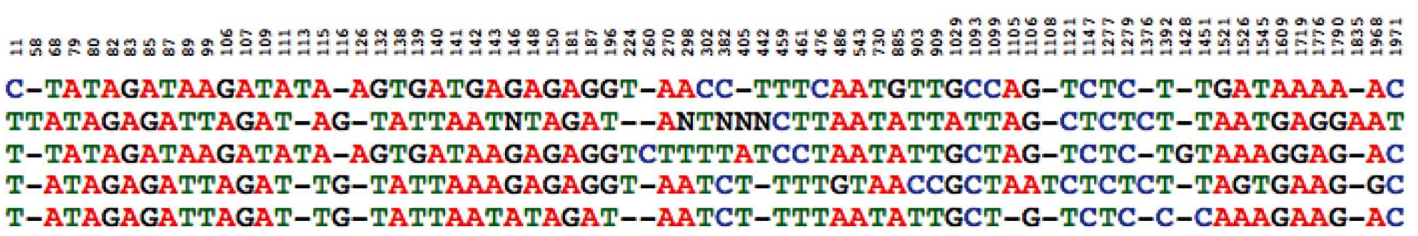

Fig. (1). Heteroplasmic sites in five copies of the coxl-minichromosome of an individual human body louse, Pediculus humanus. (A) The circular structure of the coxl-minichromosome; red lines indicate the distribution of heteroplasmic sites. (B) Heteroplasmic sites in the coding region, ie. the coxl gene. Numbers on the top row indicate the positions of these sites in the coxl gene. First, second and third codon positions are labeled as 1, 2 or 3. (C) Heteroplasmic sites in the non-coding region. Numbers on the top row indicate the positions of these sites in the non-coding region.

B

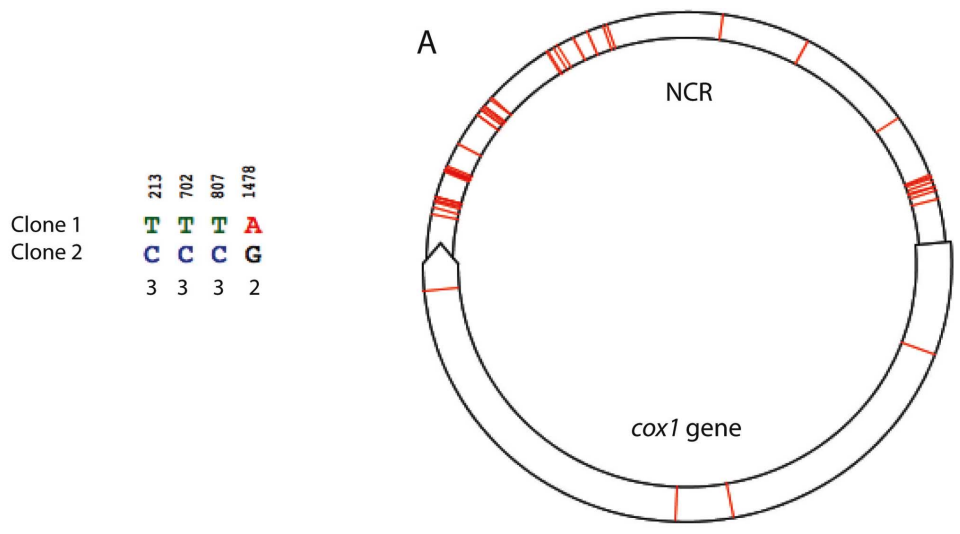

C

Fig. (2). Heteroplasmic sites in two copies of the coxl-minichromosome from an individual human head louse, Pediculus capitis. (A) The circular structure of the coxl-minichromosome; red lines indicate the distribution of heteroplasmic sites. (B) Positions of heteroplasmic sites in the coding region, ie. the coxl gene. Numbers on the top row indicate the positions of these sites in the coxl gene. Second and third codon positions are labeled as 2 or 3. (C) Heteroplasmic sites in the non-coding region. Numbers on the top row indicate the positions of these sites in the non-coding region. 
The two copies of coxl-minichromosome we sequenced from the human head louse are 2965 and 2970 bp in size. As in the human body louse, each copy of the coxlminichromosome of the human head louse has a coding region, which is 1572 bp long and contains only coxl gene, and a non-coding region (Fig. 2A). The non-coding regions of the coxl-minichromosomes of the human head louse are 1393 and 1398 bp long, respectively, which are 500 bp shorter than the non-coding regions of the human body louse (see above). Between the two copies of the coxlminichromosome of the human head louse, there are four heteroplasmic sites in the coding region (Fig. 2B), i.e. coxl gene, and 45 heteroplasmic sites in the non-coding region (Fig. 2C). One of the four heteroplasmic sites in the coxl gene is at the second codon position and the other three are at the third codon position (Fig. 2B).

\section{DISCUSSION}

Variation in $\mathrm{mt}$ genome sequence within an individual, i.e. heteroplasmy, is common in animals [4]. In arthropods, heteroplasmy has been reported previously in both noncoding regions [5, 6] and genes [7, 8]. Five heteroplasmic size variants were detected in the non-coding region of bark weevils [5], and at least two heterplasmic size variants have been detected in the non-coding region of Drosophila melanogaster [6]. Two heteroplasmic haplotypes, differentiated by four SNPs which are related to insecticide resistance, have been detected in the cytochrome $b$ gene $(c o b)$ in mites [8]. Frey and Frey (2004) measured the level of heteroplasmy in the coxl gene of Thrips tabaci; they sequenced 64 clones of the coxl gene and detected 33 heteroplasmic sites, i.e. an average of 0.5 heteroplasmic sites per clone [7]. In this study, we sequenced seven clones of the coxl gene of the human lice but we detected 17 heteroplasmic sites, i.e. 2.4 heteroplasmic sites per clone. The number of heteroplasmic sites we detected in the human lice was significantly higher than that in Thrips tabaci $(\mathrm{p}=0.001)$.

The level of heteroplasmy has been studied most, however, in humans. Pereira et al. (2009) compared the entire $\mathrm{mt}$ genome sequences of 5140 human individuals and found, in total, 120 variable sites [9]. Furthermore, He et al. (2010) sequenced the entire human $\mathrm{mt}$ genomes in extremely high coverage (on average 16,700 times) and found 34 heteroplasmic sites in 10 human individuals; only one of these 34 sites was in coxl gene [10]. In the present study, we detected, however, 17 heteroplasmic sites in coxl gene and 118 heteroplasmic sites in the non-coding region of the coxlminichromosome of the human lice. Clearly, the level of heteroplasmy in the human lice is much higher than that in humans and other animals.

Why do human lice have high level of heteroplasmy? Observed variations may be sequencing errors introduced by DNA polymerase during PCR process, or may be from nuclear integration of $\mathrm{mt}$ sequences [7]. However, these two factors cannot account for the high level of heteroplasmy observed in our study. First, the Takara La Taq DNA polymerase we used in this study has a very high accuracy: the error-rate of this polymerase is $1.7 \times 10^{-5}$ or 1.7 errors in 100,000 base pairs. At this rate, less than 0.5 mutations can be introduced into the $25,000 \mathrm{bp}$ we sequenced. Second, the nuclear genome of the human body louse has been sequenced and there is no evidence for nuclear integration of mt DNA sequence in this louse [3]. We propose that the high level of heteroplasmy observed in the human lice may be linked to the recombination between different minichromosomes of the fragmented mt genome. Shao et al. (2009) reported unequivocal evidence for recombination between five pairs of $\mathrm{mt}$ minichromosomes in the human body louse [2]. This recombination in the human body louse was attributed to the extraordinary mt genome architecture of 18 minichromosomes [2]. Recombination between $\mathrm{mt}$ minichromosomes in the human body louse led to sequence changes at a substantial number of positions in the coding regions [2]. Although there is no evidence yet for recent recombination between the coxl-minichromosome and other minichromosomes in the human body louse, we have evidence for recent recombination between the coxlminichromosome and the nad4L-minichromosome in the human pubic louse, Pthirus pubis, which is a close relative of the human body louse and the human head louse (Shao \& Barker, unpublished).

Sequences of the mt genes, in particular coxl gene, have been used in many phylogenetic studies of the human body louse and the human head louse [11-17]. Phylogenetic studies that use coxl gene sequences usually assume, explicitly or implicitly, that all copies of coxl gene in an individual animal have identical sequence, i.e. homoplasmy. Or, if only a small number of heteroplasmic sites are present, as in humans, the heteroplasmy does not confound the inference of phylogeny. The present study indicates that the human body louse and the human head louse have far more heteroplasmic sites in their coxl genes than in other animals. Whether the high level of heteroplasmy in the human lice may affect the inference of phylogeny remains to be studied.

\section{CONFLICT OF INTEREST}

Declared none.

\section{ACKNOWLEDGEMENTS}

We thank the anonymous reviewers for their comments that have greatly improved this manuscript. This research was funded by an Australian Postdoctoral Fellowship from the Australian Research Council (ARC) to R.S, and an ARC Discovery grant to R.S.and S.C.B.

\section{REFERENCES}

[1] Boore JL. Animal mitochondrial genomes. Nucleic Acids Res 1999; 27(8): 1767-80.

[2] Shao RF, Kirkness EF, Barker SC. The single mitochondrial chromosome typical of animals has evolved into 18 minichromosomes in the human body louse, Pediculus humanus. Genome Res 2009; 19(5): 904-12.

[3] Kirkness EF, Haas BJ, Sun WL, et al. Genome sequences of the human body louse and its primary endosymbiont provide insights into the permanent parasitic lifestyle. Proc Natl Acad Sci USA 2010; 107(27): 12168-73.

[4] Barr CM, Neiman M, Taylor DR. Inheritance and recombination of mitochondrial genomes in plants, fungi and animals. New Phytol 2005; 168(1): 39-50.

[5] Boyce TM, Zwick ME, Aquadro CF. Mitochondrial DNA in the bark weevils - size, structure and heteroplasmy. Genetics 1989; 123(4): 825-36. 
[6] Kann LM, Rosenblum EB, Rand DM. Aging, mating, and the evolution of mtDNA heteroplasmy in Drosophila melanogaster. Proc Natl Acad Sci USA 1998; 95(5): 2372-7.

[7] Frey JE, Frey B. Origin of intra-individual variation in MRamplified mitochondrial cytochrome oxidase I of Thrips tabaci (Thysanoptera : Thripidae): mitochondrial heteroplasmy or nuclear integration? Hereditas 2004; 140(2): 92-8.

[8] Van Leeuwen T, Vanholme B, Van Pottelberge S, et al. Mitochondrial heteroplasmy and the evolution of insecticide resistance: Non-Mendelian inheritance in action. Proc Natl Acad Sci USA 2008; 105(16): 5980-5.

[9] Pereira L, Freitas F, Fernandes V, et al. The Diversity Present in 5140 Human Mitochondrial Genomes. Am J Hum Genet 2009; 84(5): 628-40.

[10] He YP, Wu J, Dressman DC, et al. Heteroplasmic mitochondrial DNA mutations in normal and tumour cells. Nature 2010; 464(7288): 610-75.

[11] Kittler R, Kayser M, Stoneking M. Molecular evolution of Pediculus humanus and the origin of clothing. Curr Biol 2003; 13(16): 1414-7.
[12] Leo NP, Campbell NJH, Yang X, Mumcuoglu K, Barker SC. Evidence from mitochondrial DNA that head lice and body lice of humans (Phthiraptera : Pediculidae) are conspecific. J Med Entomol 2002; 39(4): 662-6.

[13] Light JE, Allen JM, Long LM, et al. Geographic distributions and origins of human head lice (Pediculus humanus capitis) based on mitochondrial data. J Parasitol 2008; 94(6): 1275-81.

[14] Light JE, Toups MA, Reed DL. What's in a name: The taxonomic status of human head and body lice. Mol Phylogenet Evol 2008; 47(3): 1203-16.

[15] Raoult D, Reed DL, Dittmar K, et al. Molecular identification of lice from pre-Columbian mummies. J Infect Dis 2008; 197(4): 535-43.

[16] Reed DL, Smith VS, Hammond SL, Rogers AR, Clayton DH. Genetic analysis of lice supports direct contact between modern and archaic humans. PLoS Biol 2004; 2(11): 1972-83.

[17] Yong Z, Fournier PE, Rydkina E, Raoult D. The geographical segregation of human lice preceded that of Pediculus humanus capitis and Pediculus humanus humanus. C R Biol 2003; 326(6): 565-74. 